\title{
Review
}

Psychopathology

Psychopathology 2019;52:161-173

Received: October 29, 2018

DOI: 10.1159/000500474

Accepted after revision: April 15, 2019

Published online: July 19, 2019

\section{Capgras' Delusion: A Systematic Review of 255 Published Cases}

\author{
Charalampos Pandis $^{\mathrm{a}}$ Niruj Agrawal ${ }^{\mathrm{b}}$ Norman Poole $^{\mathrm{b}}$ \\ ${ }^{a}$ North East London NHS Foundation Trust, Rainham, UK; ${ }^{b}$ Department of Neuropsychiatry, St. George's Hospital, \\ London, UK
}

\section{Keywords}

Capgras' syndrome - Misidentification syndrome - Cognitive neuropsychiatry $\cdot$ Psychotic disorders $\cdot$ Organic syndromes
Capgras' delusional content and associated signs point to either organic or functional aetiology. The delusion is more amorphous than many theorists have supposed, which challenges their explanatory models.

(c) 2019 S. Karger AG, Basel

\begin{abstract}
Background: Capgras' delusion has captured psychiatrists' imaginations, but the clinical features of the delusion have rarely been studied and presented systematically. Aims: The present study systematically reviews all case reports on Capgras' delusion in the English language in order to better understand differences between organic and functional aetiologies. Methods: All medical and psychiatric databases were searched, as were the bibliographies of published case reports, narrative reviews, and book chapters. Results: A total of 258 cases were identified from 175 papers. Functional Capgras' delusion was more associated with a wider variety of imposters; multiple imposters; other misidentification syndromes; auditory hallucinations; other delusions; and formal thought disorder. Organic cases were associated with age; inanimate objects; memory and visual-spatial impairments; right hemispheric dysfunction; and visual hallucinations. Executive dysfunction and aggression were associated with both types. Conclusions: Specific features of the
\end{abstract}

๑) 2019 S. Karger AG, Basel

\section{Introduction}

Capgras' delusion of misidentification has an almost totemic status in the neuroscientific understanding of psychopathology [1, 2]. The original paper [3] describing Mme M's horrific enmeshment in a logarithmic expansion of doubles reads more like a short story by Edgar Allan Poe than a medical case history. Following the death of two daughters and twin boys, she became convinced her only remaining daughter had been abducted and replaced by an imposter, who in turn was replaced by another; so, over a 4 -year period she encountered more than 2,000 doubles of her surviving daughter. Amidst this, she believed her husband had been murdered and another set in his place. The entire police force was duplicated numerous times, hence her inability to secure justice. Likewise, the doctors in the hospital multiplied, each undermining

\section{KARGER}

E-Mail karger@karger.com

www.karger.com/psp
Dr. Norman Poole

Consultant Neuropsychiatrist, Neuropsychiatry Service

2nd Floor Grosvenor Wing, St. George's Hospital

Tooting, London SW17 0QT (UK)

E-Mail norman.poole@gmail.com 
orders given by his predecessor. Explanatory models for this intriguing phenomenon seem to proliferate at a similar rate, though it was Capgras himself who set the range of options. His initial proposal was strikingly similar to contemporary $[4,5]$ cognitive neuropsychiatric accounts:

(S)ome faces that she sees with their normal features, the memory of which is not altered in any way, are nevertheless no longer accompanied by this feeling of exclusive familiarity which determines direct perception, immediate recognition [6].

In a subsequent paper, however, he and co-author Carrette co-opted Freudian explanatory concepts. A young woman's delusion that her parents were imposters could then be conceived as a solution for an erotic attachment to her father [7]. Psychodynamic theorising dominated thinking about the delusion until Gluckman's 1968 paper [8] described a case occurring in the context of proven neurological disease. Since then, a number of neuropsychiatric conditions have been associated with the onset of the delusion, somewhat undermining interpretations rooted in psychodynamic conflict.

The subsequent cognitive neuropsychiatric explanation has received considerable attention from psychiatrists, neuropsychologists, and philosophers alike; it oftentimes appears to be regarded the Rosetta stone to open the way to an explanation of all delusions. Indeed, Daniel Dennett, a renowned philosopher of neuroscience described Capgras' delusion as an "amazing phenomenon (that) should send shock waves through philosophy" [9]. Nevertheless, all theorising about Capgras' delusion appears to rest on strong assumptions about the narrowness of the delusional content. Enoch and Ball [10], for instance, described personal specificity, meaning that the delusion is generally restricted to the closest relative who is persistently misidentified. Any spread of the delusion is highly restricted to other intimates. This, however, looks nothing like Capgras' original case of Mme $M$. who reported a logarithmic expansion of doubles implicating every stratum of Parisian society. Enoch's review also reported $25-40 \%$ of cases occur in the context of diverse "organic disease," and that neuropsychological abnormalities imply predominantly right and bilateral cerebral dysfunction.

Recent prevalence studies in first episode psychosis [11] have suggested it is more common than previously supposed [12], although the measures used in the first episode population lack any specific item for the Capgras' delusion, so the reported prevalence rate of $14 \%$ must not be taken at face value. The true prevalence is thus unknown, but clinical experience would suggest that Enoch was correct to consider it rare. Nevertheless, little is known of the prognosis and response to treatment or whether there are systematic differences between Capgras' syndrome associated with "functional" and "organic" ${ }^{1}$ disorders. Previous reviews have selected only a proportion of published cases. Fleminger and Burns [13] for instance reported on 100 published cases, half having a presumed organic aetiology and the other half with functional, while Edelstyn and Oyebode's narrative review is comprehensive but does not explore the clinical features and associations statistically [14]. Combining numerous case reports and case series for statistical meta-analysis is an unusual but accepted methodology [15] that has proven able to enhance our understanding of rare conditions $[16,17]$. This study aims to collate all cases of Capgras' delusion published in the English language to better understand the clinical profile of this uncommonly important psychopathological phenomenon and to statistically explore differences between functional and organic cases.

\section{Methods}

Search and Selection Strategy for Studies

All papers published in English since Capgras' case report was published in 1923 were sought. On 31st March 2017, we searched Medline (from 1950), PsychINFO (from 1806), Embase Classic (from 1947 to 1979), and Embase (from 1980 to January 2009). We used the key words "Capgras delusion" OR "Capgras disorder" OR "misidentification disorder(s)" OR "misidentification syndrome" AND "case report(s)" AND "meta-analysis" OR "systematic review" OR "literature review." The titles and abstracts online were reviewed by the authors, and we obtained copies of all publications that appeared relevant to the study question. The reference lists of all these publications were then hand searched for additional relevant studies. Papers were excluded if they presented a misidentification syndrome other than Capgras' delusion.

\section{Data Extraction and Analysis}

Two authors (N.P. and C.P.) independently extracted all the relevant data from the papers, and where they disagreed a third reviewer (N.A.) was consulted. The following information was collected systematically and entered into a Microsoft Excel database: title, journal, year of publication, age, gender, marital status, comorbidities (medical and psychiatric), alcohol, substances, family psychiatric history, relationship with imposter, animate/inanimate double, duration of delusion, comorbid psychiatric symp-

Both "functional" and "organic" are less than satisfactory terms. Functional should be understood as psychiatrists have historically done so, rather than in the modern sense of functional neurological disorder. Organic is also outdated but is commonly employed in clinical practice and the literature. Hereafter, we drop the "scare quotes" around both terms while acknowledging their limitations. 
Box 1.

Organic Capgras' delusion [38]: A 40-year-old right-handed woman with a history of childhood-onset treatment-resistant complex partial and generalized tonic-clonic seizures. No personal or family history of psychiatric disorder. She suddenly developed the belief that family members had been replaced by similar looking imposters. The delusion emerged during a period of significantly improved seizure control. MRI findings revealed right hemispheric atrophy, SPECT demonstrated hypoperfusion in the entire right hemisphere, while there was bilateral and diffuse slowing of her EEG with no definite epileptiform activity. Risperidone and propericiazine was associated with resolution of the delusion and reduction of the right hemispheric hypoperfusion.

Functional Capgras' delusion [39]: A 37-year-old right-handed woman with no past medical or family history complained that her father, cousin, and work colleagues had been replaced. Closer examination revealed a number of associated paranoid and persecutory delusions with incongruent affect. She had reported a similar delusional belief at 17 , was seen once by a psychiatrist before the symptoms resolved within a month. All investigations, including CT scan, routine blood and urinary tests, EEG, and neurological examination, were normal. Neuropsychological testing revealed minor attentional and memory impairment consistent with a primary psychiatric disorder plus some unexplained dysnomia. Her symptoms improved on haloperidol, and she was discharged with a diagnosis of paranoid schizophrenia. toms, co-occurring misidentification delusions, neuropsychological investigations and results, neuro-imaging results (type and location of lesion), EEG. Not all parameters were available in every case reported; unreported parameters were not included in the analyses.

In addition to describing the clinical features of Capgras' delusion with the use of frequency statistics, we analysed whether these differed between cases with an organic and those with an underlying functional diagnosis (see Box 1 for paradigmatic cases of functional and organic Capgras' delusion). All the variables were then associated with organic versus functional by cross-tabulation (Pearson's $\chi^{2}$ ). Fischer's exact test was used when one or more cells in the $2 \times 2$ table contained 5 cases or fewer. Odds ratios and $95 \%$ CIs were calculated on Microsoft Excel for Windows and a $p$ value less than 0.05 was considered significant.

\section{Results}

We identified 218 papers, 175 of which were found to meet the study inclusion criteria (see Appendix 1 for references). The papers reported 258 cases presenting with Capgras' delusion. Of these, 144 described the delusion
Table 1. Underlying diagnoses

\begin{tabular}{lc}
\hline Diagnosis & $n(\%)$ \\
\hline Functional & $144(56)$ \\
Schizophrenia & $83(32)$ \\
Schizoaffective & $16(6)$ \\
Transient psychotic episode & $2(<1)$ \\
Delusional disorder & $8(3)$ \\
Bipolar affective disorder & $6(3)$ \\
Psychotic depression & $15(6)$ \\
OCD & $3(1)$ \\
Other & $11(4)$ \\
\hline Organic & $111(43)$ \\
Delirium & $9(3)$ \\
Dementia & $39(15)$ \\
$\quad$ Parkinson's disease dementia & $10(4)$ \\
$\quad$ Lewy body dementia & $5(2)$ \\
$\quad$ Alzheimer's disease & $6(2)$ \\
Vascular & $3(1)$ \\
Unspecified & $15(6)$ \\
Organic delusional disorder & $50(19)$ \\
Drug related & $7(3)$ \\
TBI & $6(2)$ \\
\hline Mixed functional and organic & $2(<1)$ \\
Not stated & $1(<1)$ \\
\hline Total & 258 \\
\hline \multicolumn{2}{c}{ a Unstated in 8 cases, puerperal psychosis, etc. } \\
\hline
\end{tabular}

occurring in the context of functional psychiatric disorder, with 111 having an identified organic aetiology. The breakdown of primary psychiatric disorders is shown in Table 1 . The most frequent diagnoses were schizophrenia $(n=83 ; 32 \%)$, followed by organic psychosis $(n=50 ; 19 \%)$ and dementia $(n=39 ; 15 \%)$. This was predominantly unspecified dementia $(n=15)$ followed by Lewy body/Parkinson's disease dementia $(n=15 ; 6 \%)$. Two cases were reported as a combination of functional and organic aetiology, while one case report did not discuss underlying diagnosis at all. These three were therefore removed from the statistical analyses in Table 2; hence, the total number of cases analysed was 255 .

The first case reported in the English language was published in 1963, and the most recent in 2016. The male to female ratio was 1:1.4. The median age of all cases was 45 ranging from 8 to 94 years old. The median age of cases reported to have a "functional" diagnosis was 37 (SD 15.87), while it was 64 (SD 19.68) in the "organic" group. This difference was highly significant statistically $(p<0.01)$. Before 1990 , the percentage of functional diagnoses constituted 
Table 2. Clinical features of functional vs. organic aetiology

\begin{tabular}{|c|c|c|c|c|c|c|}
\hline & $\begin{array}{l}\text { Total } \\
n(\%)\end{array}$ & $\begin{array}{l}\text { Functional } \\
n(\%)\end{array}$ & $\begin{array}{l}\text { Organic } \\
n(\%)\end{array}$ & $\begin{array}{l}\text { Cross- } \\
\text { tabulation }\end{array}$ & Odds ratio & $95 \% \mathrm{CI}$ \\
\hline Cases & 255 & $144(56)$ & $111(44)$ & & & \\
\hline \multicolumn{7}{|l|}{ Gender } \\
\hline Female & $148(58)$ & $90(62)$ & $58(52)$ & 2.7 & 0.66 & $0.40-1.08$ \\
\hline Male & $107(42)$ & $54(38)$ & $53(48)$ & 2.7 & 1.52 & $0.92-2.51$ \\
\hline Age, median (SD), years & $47(19.29)$ & $36(15.87)^{* *}$ & $64(19.68)^{* *}$ & & & \\
\hline \multicolumn{7}{|l|}{ Ilius } \\
\hline Spouse & $96(38)$ & $41(28)$ & $55(50)$ & 11.86 & $2.47^{* *}$ & $1.47-4.14$ \\
\hline Parent & $68(27)$ & $51(35)$ & $17(15)$ & 12.95 & $0.33^{* *}$ & $0.18-0.61$ \\
\hline Child & $41(16)$ & $25(17)$ & $16(14)$ & 0.4 & 0.8 & $0.41-1.58$ \\
\hline Sibling & $25(10)$ & $17(12)$ & $8(7)$ & 1.5 & 0.58 & $0.24-1.39$ \\
\hline 2nd degree relative & $9(4)$ & $6(4)$ & $3(3)$ & 0.4 & 0.64 & $0.15-2.61$ \\
\hline Stranger & $26(10)$ & $21(15)$ & $5(5)$ & 6.95 & $0.27 *$ & $0.10-0.76$ \\
\hline Subjective double & $25(10)$ & $20(14)$ & $5(5)$ & 6.24 & $0.29 *$ & $0.10-0.80$ \\
\hline Multiple imposters & $100(39)$ & $66(46)$ & $34(31)$ & 6.07 & $0.52^{* *}$ & $0.31-0.87$ \\
\hline Inanimate object & $43(17)$ & $15(10)$ & $28(25)$ & 9.8 & $2.9^{* *}$ & $1.46-5.75$ \\
\hline \multicolumn{7}{|l|}{ Associated symptoms } \\
\hline Paranoid delusions & $89(35)$ & $61(42)$ & $28(25)$ & 7.28 & $0.46^{* *}$ & $0.27-0.8$ \\
\hline Dissociation & $7(3)$ & $6(4)$ & $1(1)$ & 2.5 & 0.20 & $0.02-1.76$ \\
\hline Affective & $133(52)$ & $83(58)$ & $50(45)$ & 3.98 & 0.61 & $0.37-1.02$ \\
\hline Aggression & $81(32)$ & $55(38)$ & $26(23)$ & 6.6 & $0.49^{*}$ & $0.28-0.86$ \\
\hline Homicide & $9(4)$ & $8(6)$ & $1(1)$ & 3.98 & $0.15^{*}$ & $0.01-1.25$ \\
\hline \multicolumn{7}{|l|}{ Hallucinations } \\
\hline Auditory & $64(25)$ & $51(35)$ & $13(12)$ & 18.73 & $0.24^{* *}$ & $0.12-0.47$ \\
\hline Visual & $33(13)$ & $12(8)$ & $21(19)$ & 6.2 & $2.6^{*}$ & $1.20-5.5$ \\
\hline Other misidentification synd. & $21(8)$ & $18(12.5)$ & $3(3)$ & 7.9 & $0.01^{* *}$ & $0.06-0.68$ \\
\hline Formal thought disorder & $32(12.5)$ & $24(17)$ & $8(7)$ & 5.1 & $0.38^{*}$ & $0.17-0.9$ \\
\hline \multicolumn{7}{|l|}{ Responds to treatment } \\
\hline Partial or good response & $165(65)$ & $98(68)$ & $67(60)$ & 0.06 & 1.20 & $0.53-2.35$ \\
\hline
\end{tabular}

$64 \%$ of the total reported, while after that year they comprised $53 \%$ of all the cases representing a trend but not a statistically significant reduction $\left(\chi^{2}=3.1908 ; p=0.08\right)$. In terms of quality of the case reports, $21 \%$ of them included $75 \%$ or more of the parameters of interest; another $58 \%$ described between 50 and $74 \%$ of the parameters; while the remainder described $49 \%$ or fewer. Nearly $80 \%$ of the case reports can be considered of moderate quality or above.

The clinical features of Capgras' delusion are presented in Table 2. There was no difference in gender between organic and functional groups. There were, however, numerous differences between organic and functional cases with regard the person's relationship to the imposter. Misidentifications concerning the spouse and inanimate objects were statistically significant for the organic causes of the delusion, whereas misidentifying a parent or stranger, the syndrome of subjective double, and multiple imposters were all significantly associated with functional disorders. Symptoms associated with Capgras' delusion also differed between organic and functional cases. Additional delusions, auditory hallucinations, homicide, aggression, and other misidentification syndromes were significantly more frequent when the delusion occurred in the context of a functional psychiatric disorder. Formal thought disorder was also significantly more associated with functional than organic disorders. Visual hallucinations were statistically more frequent in organic causes of the delusion. The duration of the Capgras delusion in functional disorders ranged from 3 days to over 10 years, while in organic conditions, it was reported from 1 week to over 10 years. 
Table 3. Investigations

\begin{tabular}{|c|c|c|c|c|c|c|c|c|}
\hline & \multirow[t]{2}{*}{ Total } & \multicolumn{2}{|l|}{ Functional } & \multicolumn{2}{|l|}{ Organic } & \multirow{2}{*}{$\begin{array}{l}\text { Cross- } \\
\text { tabulation }\end{array}$} & \multirow[t]{2}{*}{ OR } & \multirow[t]{2}{*}{$\mathrm{CI}$} \\
\hline & & completed & abnormal & completed & abnormal & & & \\
\hline Neuropsych. testing & 129 & & & & & & & \\
\hline Memory & 78 & 28 & $15(55)$ & 50 & $41(82)$ & 7.16 & $3.9^{*}$ & $1.4-11.11$ \\
\hline Language & 50 & 19 & $5(26)$ & 31 & $15(48)$ & 2.39 & 2.62 & $0.76-9.07$ \\
\hline Visuospatial & 56 & 23 & $9(39)$ & 33 & $24(72)$ & 6.32 & $4.41^{*}$ & $1.33-12.9$ \\
\hline Visuoperception & 53 & 26 & $13(50)$ & 27 & $14(52)$ & 0.02 & 1.07 & $0.36-3.16$ \\
\hline Executive & 69 & 28 & $17(60)$ & 41 & $33(80)$ & 3.26 & 2.67 & $0.9-7.88$ \\
\hline EEG & 104 & 61 & $12(20)$ & 43 & $28(65)$ & 21.04 & $7.35^{* *}$ & $3.01-17.95$ \\
\hline Neuroimaging & 161 & 77 & $21(27)$ & 84 & $56(67)$ & 24.98 & $2.44^{* *}$ & $1.35-4.40$ \\
\hline
\end{tabular}

Figures in parentheses indicate percentages. ${ }^{*} p<0.05$; ${ }^{* *} p<0.01$.

Table 2 shows that $65 \%$ of all cases were considered to have responded well to treatment, with no discernible difference in response rates between groups. Antipsychotic medications were reported to be prescribed in 165 of cases, including clozapine (10). Of these, some were co-prescribed an antidepressant medication (27), benzodiazepines (10), lithium (9), anti-dementia medication (8), and anti-epileptic mood stabilisers (16). The use of other physical treatments was relatively rare: ECT (17), insulin coma therapy (4), leucotomy (1), cingulotomy (2), intravenous immunoglobulin therapy (1), and deep brain stimulation (1).

Table 3 presents differences between functional and organic groups in terms of neuroimaging, EEG, and neuropsychological testing. As one would anticipate, memory and visuospatial were more commonly impaired in organic cases, as were EEG and neuroimaging abnormalities. Of the 258 cases identified, 161 (62\%) underwent some form of neuroimaging. CT was the most frequent method $(109 ; 68 \%)$ followed by MRI $(47 ; 29 \%)$, and then SPECT (14; 9\%). Those reported as organic Capgras' delusion were significantly more likely to demonstrate some abnormality on neuroimaging. $67 \%$ of such cases did so against $27 \%$ of those with functional Capgras. Of those with identifiable abnormalities, global atrophy was found in $57(35 \%)$ and a fronto-temporal pattern of atrophy in 29 (12\%). Typically, however, only laterality of the atrophy or lesion was reported giving a ratio left:bilateral:right of lateralisation of $7: 14: 14$. Therefore, $80 \%$ of the cases that had identifiable cerebral pathology demonstrated an abnormality involving the right hemisphere. Likewise, 37 (35\%) of the 107 cases who had an EEG were found to have some form of abnormality, predominantly in the right hemisphere (L:R; 2:7).

Capgras' Delusion: A Meta-Analysis of Case Reports

\section{Discussion}

This study collates all cases of Capgras' delusion reported in the English language medical literature since the first case report was published in 1963 . When cases were first published in English, Capgras' delusion was believed to occur mainly in schizophreniform psychoses [18], and explanations for the peculiar content were sought exclusively in terms of interpersonal dynamics. The intimacy of the relationship and conceptual frameworks of the time precluded alternative forms of explanation. Since Ellis and Young's seminal paper in 1990 [4], which revived Capgras' original explanation that the delusion occurs due to the loss of affective familiarity for faces in the presence of intact facial recognition, the proportion of cases describing the delusion in the context of neurological disorder has increased, as has the utilisation of physical and neuropsychological investigations. Thus, cognitive neuropsychiatric accounts for the delusion and its particular content are ascendant.

While 258 case reports over a 52 -year-period averages just 5 cases annually, there was a very definite increase in reporting of cases in the late 1980s that peaked in the years 1990-1994. Comparing this study to a thorough review of the misidentification syndromes conducted over 25 years ago [19], we found a smaller proportion of cases were attributed to functional psychiatric disorders and corresponding higher rate of organic aetiologies. In that paper, $73 \%$ of the Capgras' delusion cases had an underlying diagnosis of schizophrenia, and $26 \%$ were associated with neurological disorders, against 32 and $43 \%$, respectively, for ours. Nevertheless, schizophrenia remains the largest single disorder associated with case reports of Capgras' delusion and organic delusional disorder, with its multifarious medical aetiologies, a distant second at 19\%. 
Unsurprisingly, the mean age of cases in functional and organic presentations differs. Nevertheless, given schizophreniform illnesses tend to present in the late teens and early twenties the mean age ( 36 years) of cases with a functional Capgras' delusion is old, but probably reflects the long mean duration of the delusion in the functional group. Those with neurological disorder associated with onset of the delusion had a mean age of 64 and large standard deviation, in keeping with their presentation in middle to late adulthood, especially as Capgras' delusion in dementia tends to occur in the later stages [18].

The identity of the imposter is significantly associated with the reported underlying aetiology. Those whose Capgras' delusion is reportedly due to functional psychiatric disorder are more likely to view their parent as an imposter, whereas the spouse is implicated in those with suspected neurological aetiology. This is likely a function of the different mean age for the groups, as older cases will be closest to a long-term partner having already achieved independence from their parents. If so, this supports the role of intimacy in the Capgras' delusion in keeping with both the psychodynamic and neurocognitive interpretations. Against this, however, is the frequency with which strangers and multiple imposters are implicated in all cases of Capgras' delusion - at 10 and 39\%, respectively - and the not infrequent involvement of inanimate objects (17\%). Indeed, it is difficult to support either type of theory when around a quarter of cases present with such incompatible content. Multiple imposters are significantly more likely to occur in functional cases, while the involvement of inanimate objects would seem to suggest organic aetiology.

De-realisation/depersonalisation has been described as an occasional component in the genesis of the delusional belief [20] and, accordingly, it was described only rarely in these cases. Its scarcity might be thought to undermine Christodoulou's theory [21] that Capgras' delusion is a consequence of extreme depersonalisation but that author suggested the delusion developed as a means of ameliorating distressing strangeness and unreality. The question of why depersonalisation is resolved this way in some but not others is left unanswered.

As has been described previously [18, 22], aggression and even homicide are frequently associated with Capgras' delusion. Homicide was reported in $6 \%$ of the functional cases, which might indicate the delusion is even riskier than previously thought or, more likely, represents publication bias. While infrequent, homicide was statistically associated with functional disorder $(p=0.045)$. Al- though aggression was significantly associated with functional $(38 \%)$ rather than organic aetiology, it was nevertheless a relatively frequent finding in the latter (23\%). This moderate association with violence is clinically important but, from another perspective, raises puzzling philosophical questions. Why do the non-violent Capgras sufferers, who constitute the majority, seem to live peaceably with their imposter? The frequent failure to act on the delusional content has motivated some to question the rationality of those suffering with Capgras' syndrome [23] and even whether delusions are beliefs at all [24]. Such considerations are outside the scope of this review, but the answers bear on the coherence of competing theoretical models. A one-stage model of delusion formation, such as Maher's [25], implies that rationality is preserved and the delusional belief should be reasonably well integrated. Two-stage models, on the other hand, posit an additional factor such as paranoid and suspicious mood [11] or impaired monitoring and evaluation of newly formed beliefs [2], which diminishes their status as such. The two-stage model is more compatible with the inaction and acquiescence noted in these case reports.

Other misidentification syndromes co-occurred in nearly 1 in 7 of the functional cases (13\%) but were rare in the organic ones (3\%), a statistically significant difference. The greater reporting of visual hallucinations in the organic group (19 vs. $8 \%$ ) is unsurprising given they are considered almost pathognomonic of cerebral dysfunction [26] but could also suggest that perceptual abnormality plays a role in those cases. Conversely, auditory hallucinations were significantly more common in functional (35\%) than organic cases (12\%). Given many organic causes of the delusion would be neurodegenerative in nature, it is somewhat surprising that treatment was equally effective in both groups, with two-thirds of all case reports describing a favourable outcome.

As is to be expected, neuropsychological, neuroimaging, and EEG abnormalities were significantly more common in the organic group. However, neuropsychological abnormalities in all domains were commoner than might have been supposed in the functional group, while visuospatial and memory impairments were especially associated with organic aetiology. This finding superficially accords with a literature emphasising memory impairment in misidentification syndromes [27]. It is an occipito-hippocampal disconnect between stored memories and new experiences that is, however, suggested as the cause of the misidentification rather than impaired memory per se. Executive dysfunction occurred in 63 and $78 \%$ of functional and organic cases, respectively, a difference that 
was not statistically significant. This very high rate of executive impairment in both groups is in keeping with two-stage models of delusion formation which blame faulty reasoning for the apparent bizarreness, irrationality, and incorrigibility of delusional content [28, 29]. Where cerebral dysfunction has been demonstrated, it overwhelmingly implicates the right hemisphere, compatible with Cutting's hypothesis that judging familiarity is a non-dominant function [30]. Yet the failure to recognise people and objects associated with widespread dysfunction in one hemisphere is difficult to reconcile with the narrow focus of Capgras' delusion or its frequently bizarre content. This result also differs from the study by Bell et al. [31], which identified 84 cases of Capgras' delusion. Of these, 40 underwent some form of neuroimaging, but abnormalities were detected in only 14 . A right-sided abnormality was the least common finding in their series, with diffuse bilateral pathology the commonest (9/14). A more recent similar study identified a further 34 patients with Capgras' delusion from the electronic records of a London Mental Health Trust. Only 7 of these had neuroimaging reported, and none showed a right lateralised neuropathology. It may be that these populations, drawn from two inner-London healthcare providers, may not represent the Capgras' delusion patients who are deemed worthy of publication as case reports in neurology and psychiatry journals. Specifically, given the mental health setting, the two studies may be largely identifying cases that would be regarded as functional in this paper. Nevertheless, these discrepancies are significant and worthy of further investigation [32].

It was at one time suggested that Capgras' delusion arose as a consequence of impaired facial recognition, similar to prosopagnosia. However, this was soon discounted as the conditions bore little similarity upon closer analysis [10]. In fact, a double dissociation has been found between prosopagnosia and Capgras' delusion. Prosopagnostics have a preserved skin conductance response (SCR), a proxy for emotional arousal, but impaired explicit identification of familiar faces. Cases of Capgras' delusion demonstrate the obverse, with loss of affective familiarity with intact identification. It is this mismatch between emotional and intellectual recognition that is said to give rise to the delusional belief in imposters. The abnormal SCR was demonstrated in a case recently described by Bobes et al. [33] alongside diffusion tensor imaging abnormalities in the inferior fronto-occipital fasciculus (IFOF) and intact inferior longitudinal fasciculus. These pathways are believed to subserve respectively emotional and explicit facial recognition. In-

Capgras' Delusion: A Meta-Analysis of Case Reports terestingly, the IFOF abnormality was confined to the left hemisphere, which contradicts our finding that neuroimaging predominantly implicates right hemispheric pathology.

Because many, albeit fewer, of the functional patients demonstrated neuroimaging and neuropsychological abnormalities, the results seem to support the proposal by White et al. [34] and others [35] to end the distinction between neurological and psychiatric disorder implicit in the functional/organic dichotomy employed here. However, acknowledging the involvement of the brain in mental disorders does not necessitate a merger of the fields [36]. A recent meta-analysis of neuroimaging findings in psychiatric and neurological conditions found that there are differences in the regions and networks involved [37]. There was greater involvement of the basal ganglia, insula, lateral and medial temporal cortex, and sensorimotor in neurological disorders with the medial frontal cortex, anterior and posterior cingulate, superior frontal gyrus, and occipital cortex disproportionately affected in mental disorders. The differences between the functional and organic Capgras' delusion can therefore be a helpful clinical pointer towards the correct underlying aetiology.

This study is limited by the variable quality of case reports and publication bias. Only $21 \%$ of case reports were graded as high quality, so important clinical information including results of investigations was missing in $79 \%$ of the cases analysed, which introduces a bias that limits the interpretability of the findings. This probably affected disproportionately those considered functional cases, as they are likely to have been less extensively investigated, so abnormalities may have gone undetected. Some cases could be spuriously labelled organic due to a concurrent but causally irrelevant medical diagnosis, while truly organic cases might have wrongly received a functional diagnosis, particularly in those reports predating the widespread use of neuroimaging and other investigations. There is little standardisation to guide the writing of case reports, so the quality of description therein depends on the most salient features of the case and idiosyncrasies of the authors. It would be helpful if future case reports gathered detailed information on the phenomenology of the delusion, the subject's personal and medical background, plus investigations including neuroimaging, EEG, and neuropsychological testing. The steadily rising proportion of organic Capgras' delusion is unlikely to reflect increased prevalence, instead demonstrating that case reports follow fashions in theory; an instance of confirmation bias strengthening belief in the cognitive neuro- 
psychiatric account of the delusion that stimulates additional case reports in a similar vein. The findings in this review must therefore be interpreted with great caution. The features of a case that make it suitable for publication probably means it is not representative of Capgras' delusion cases generally. Our frequency statistics should not be taken as epidemiological.

\section{Conclusions}

Capgras' delusion is a fascinating psychopathological phenomenon that presents in a wide range of psychiatric and neurological disorders with subtly differing patterns dependent on the underlying aetiology. The difference between organic and functional cases is at the level of delusional content, associated psychopathology, neuropsychological findings, and biomedical investigations. An underlying neurological disease should be suspected where the delusion concerns a spouse or inanimate objects and is associated with visual hallucinations, while a functional disorder is suggested by multiple imposters, strangers, subjective double, additional delusions, and auditory hallucinations. Fortunately, most sufferers can expect a good response to antipsychotic medication, irrespective of aetiology, but the clinician should always be mindful of the risk of aggression and homicide.

It is worth noting that the circumscribed delusion about which theorists speculate bears limited comparison to the clinical phenomena reported here and elsewhere [31]; the delusion appears more amorphous than theorists have supposed. If Capgras' delusion is to become the Rosetta stone for delusion generally, then their theories need to account for the delusion as it is actually encountered, lest they be accused of jumping to conclusions and other reasoning errors.

\section{Disclosure Statement}

None of the authors have anything to declare.

\section{Author Contributions}

C.P. and N.P. were involved in originating and developing the research question. C.P., N.P., and N.A. were involved in data gathering and analysis. C.P. and N.P. were involved in writing the first draft of the paper with comments and feedback from N.A. for subsequent drafts.

\section{Appendix}

1. Abbate C, Trimarchi PD, Salvi GP, Quarenghi AM, Vergani C, Luzzatti C: Delusion of inanimate doubles: Description of a case of focal retrograde amnesia. Neurocase 2012;18:457-477.

2. Abed RT, Fewtrell WD: Delusional misidentification of familiar inanimate objects. A rare variant of Capgras syndrome. The British Journal of Psychiatry 1990;157:915-917.

3. Alexander MP, Stuss DT, Benson DF: Capgras syndrome A reduplicative phenomenon. Neurology 1979;29:334-339.

4. Anderson DN: The delusion of inanimate doubles. Implications for understanding the Capgras phenomenon. The British Journal of Psychiatry 1988;153:694-699.

5. Antérion CT, Convers P, Desmales S, Borg C, Laurent B: An odd manifestation of the Capgras syndrome: Loss of familiarity even with the sexual partner. Neurophysiologie Clinique/ Clinical Neurophysiology 2008;38:177-182.

6. Apaydin H, Benbir G: Capgras syndrome associated with Parkinson's disease dementia: Report of two cases. Alzheimer's \& Dementia: The Journal of the Alzheimer's Association. 2013; 9:P733-P734.

7. Atta K, Forlenza N, Gujski M, Hashmi S, Isaac G: Delusional misidentification syndromes: separate disorders or unusual presentations of existing DSM-IV categories? Psychiatry 2006; 3:56.

8. Atwal S, Khan MH: Coexistence of Capgras and its related syndromes in a single patient. Australian and New Zealand Journal of Psychiatry 1986;20:496-498.

9. Aziz MA, Razik GN, Donn JE: Dangerousness and management of delusional misidentification syndrome. Psychopathology 2005;38:97-102.

10. Aziz VM, Warner NJ: Capgras' syndrome of time. Psychopathology 2005;38:49-52.

11. Baldwin RC, Snowden JS, Mann D: Delusional misidentification in association with cortical lewy body disease - a case report and overview of possible mechanisms. International Journal of Geriatric Psychiatry 1995;10:893-898.

12. Barton JL: Delusional misidentification and platelet monoamine oxidase. Biological Psychiatry 1980;15:275-282.

13. Banov MD, Kulick AR, Oepen G, Pope HG: A new identity for misidentification syndromes. Comprehensive Psychiatry 1993; 34:414-417.

14. Bekelman DB: Capgras syndrome associated with morphine treatment. Journal of Palliative Medicine 2006;9:810-813.

15. Berson RJ: Capgras' syndrome. The American Journal of Psychiatry 1982;140:969-978.

16. Bhatia MS: Capgras syndrome in a patient with migraine. The British Journal of Psychiatry 1990;157:917-918.

17. Bhatia MS, Singhal PK, Agrawal P, Malik SC: Capgras syndrome in chloroquine induced psychosis. Indian Journal of Psychiatry 1988;30:311.

18. Bienenfeld D, Brott T: Capgras' syndrome following minor head trauma. The Journal of Clinical Psychiatry 1989;50:68-69.

19. Bland RC: Capgras' Syndrome: A Case Report. Canadian Psychiatric Association Journal 1971;16:369-371.

20. Bobes MA, Góngora D, Valdes A, Santos Y, Acosta Y, Garcia YF, Lage A, Valdés-Sosa M: Testing the connections within face processing circuitry in Capgras delusion with diffusion imaging tractography. NeuroImage: Clinical 2016;11:30-40. 
21. Bouckoms A, Martuza R, Henderson M: Capgras syndrome with subarachnoid hemorrhage. The Journal of Nervous and Mental Disease 1986;174:484-488.

22. Brighetti G, Bonifacci P, Borlimi R, Ottaviani C: "Far from the heart far from the eye": evidence from the Capgras delusion. Cognitive Neuropsychiatry 2007;12:189-197.

23. Brooks DM, Reish AG, Segal M, Williams K: Poster 24: Capgras Syndrome After Deep Brain Stimulator Placement for Parkinson Disease: A Case Report. PM \& R 2010;2:S18.

24. Burjorjee RN, Al-Adawi S: Delusional misidentification of Capgras: a case report from Oman. Journal of Nervous and Mental Disease 1992;180:733-734.

25. Burns AL: The oldest patient with Capgras syndrome? The British Journal of Psychiatry. 1985;147:719-720.

26. Butler PV: Diurnal variation in Cotard's syndrome (copresent with Capgras delusion) following traumatic brain injury. Australian \& New Zealand Journal of Psychiatry 2000;34:684-687.

27. Canagasabey B, Katona CL: Capgras syndrome in association with lithium toxicity. The British Journal of Psychiatry 1991; 159:879-881.

28. Carabellese F, Rocca G, Candelli C, Catanesi R: Mental illness, violence and delusional misidentifications: The role of Capgras' syndrome in matricide. Journal of Forensic and Legal Medicine 2014;31:9-13.

29. Casu G, Cascella N, Maggini C: Homicide in Capgras' syndrome. Psychopathology 1994;27:281-284.

30. Castillo PM, Berman CW: Delusional gross replacement of inanimate objects. The British Journal of Psychiatry 1994;164: 693-696.

31. Cavanagh PJ: Delusional misidentification secondary to perceptual abnormality: An unusual case of Capgras syndrome. International Journal of Psychiatry in Clinical Practice 2000;4: 245-247.

32. Cawte J, Tarrant M: Capgras' syndrome: outmoded term for challenging delusions? Australian \& New Zealand Journal of Psychiatry 1984;18:388-390.

33. Cercy SP, Marasia JC: Combined delusional misidentification syndrome in a patient with Parkinson's disease. The Journal of Neuropsychiatry and Clinical Neurosciences 2012;24:E3-E4.

34. Chawla S, Buchan T, Galen N: Capgras syndrome: a case report from Zimbabwe. The British Journal of Psychiatry 1987;151: 254-256.

35. Christodoulou GN: The syndrome of Capgras. The British Journal of Psychiatry 1977;130:556-564.

36. Collins MN, Hawthorne ME, Gribbin N, Jacobson R: Capgras' syndrome with organic disorders. Postgraduate Medical Journal 1990;66:1064-1067.

37. Cooper SA, Collacott RA: Delusional misidentification syndromes in a woman with mild learning disabilities. Irish Journal of Psychological Medicine 1996;13:70-72.

38. Corlett PR, D'Souza DC, Krystal JH: Capgras syndrome induced by ketamine in a healthy subject. Biological Psychiatry 2010;68:e1-e2.

39. Crichton P, Lewis S: Delusional misidentification, AIDS and the right hemisphere. The British Journal of Psychiatry 1990; 157:608-610.

40. Dalgalarrondo P, Fujisawa G, Banzato CE: Capgras syndrome and blindness: Against the prosopagnosia hypothesis. The Canadian Journal of Psychiatry 2002;47:387-388.
41. Dally P, Gomez J: Capgras: Case study and reappraisal of psychopathology. Psychology and Psychotherapy: Theory, Research and Practice 1979;52:291-295.

42. Daniel DG, Swallows A, Wolff F: Capgras delusion and seizures in association with therapeutic dosages of disulfiram. Southern Medical Journal 1987;80:1577-1579.

43. Darby RR, Caplan D: “Cat-gras” delusion: a unique misidentification syndrome and a novel explanation. Neurocase 2016;22: 251-256.

44. Dejode JM, Antonini F, Lagier P, Martin C: Case report: Capgras syndrome: a clinical manifestation of watershed cerebral infarct complicating the use of extracorporeal membrane oxygenation. Critical Care 2001;5:232.

45. De Leo D, Galligioni S, Magni G: A case of Capgras delusion presenting as a postpartum psychosis. The Journal of Clinical Psychiatry 1985;46:242-243.

46. Delaffon V, Vahabzadeh A, Naik S, Kinnair D, Bruce J: Capgras Syndrome in a Patient with Severe Hyponatraemia. German Journal of Psychiatry 2010;13:175-177.

47. Diard-Detoeuf C, Desmidt T, Mondon K, Graux J: A case of Capgras syndrome with one's own reflected image in a mirror. Neurocase 2016;22:168-169.

48. Dietl T, Herr A, Brunner H, Friess E: Capgras syndrome-out of sight, out of mind? Acta Psychiatrica Scandinavica 2003;108: 460-462.

49. Donnelly R, Bolouri MS, Prashad SJ, Coverdale JH, Hays JR, Kahn DA: Comorbid Diogenes and Capgras syndromes. Journal of Psychiatric Practice 2008; 14:312-317.

50. Edelstyn NM, Oyebode F: Letter to the editor: Capgras syndrome in the context of multiple myeloma. International Journal of Geriatric Psychiatry 1998;13:645-646.

51. Edelstyn NM, Oyebode F, Barrett K: Delusional misidentification: A neuropsychological case study in dementia associated with Parkinson's disease. Neurocase 1998;4:181-188.

52. Enoch MD. The Capgras syndrome. Acta Psychiatrica Scandinavica 1963;39:437-462.

53. Estrada-Bellmann I, Ulloa-Escobar Y, Barbosa-Flores SL, Pech-George RE, González-Trevino R, Conde-Gómez L, Marfil-Rivera A: Capgras syndrome as a psychiatric manifestation in Parkinson's disease: A case report and literature review. Medicina Universitaria 2015;17:49-52.

54. Faber R, Abrams R: Schizophrenia in a 47, XYY male. The British Journal of Psychiatry 1975;127:401-403.

55. Fialkov MJ, Robins AH: An unusual case of the Capgras syndrome. The British Journal of Psychiatry 1978;132:403-404.

56. Fils JM, Stewart JT: Capgras syndrome related to left-hemisphere injury. The Journal of Neuropsychiatry and Clinical Neurosciences 2011;23:E6.

57. Foerstl H: Capgras' delusion: an example of coalescent psychodynamic and organic factors. Comprehensive Psychiatry 1990; 31:447-449.

58. Förstl H, Almeida OP, Iacoponi E: Capgras delusion in the elderly: The evidence for a possible organic origin. International Journal of Geriatric Psychiatry 1991;6:845-852.

59. Frazer SJ, Roberts JM: Three cases of Capgras' syndrome. The British Journal of Psychiatry 1994;164:557-559.

60. Fishbain DA: Dangerous delusions: violence and the misidentification syndromes. The British Journal of Psychiatry 1988; 152:859-860. 
61. Fischer C, Keeler A, Fornazzari L, Ringer L, Hansen T, Schweizer TA: A Rare Variant of Capgras Syndrome in Alzheimer's Disease. Canadian Journal of Neurological Sciences/Journal Canadien des Sciences Neurologiques 2009;36:509-511.

62. Gibson RC, Lowe GA, Morgan KA, Henry M, De La Haye W, Irons A: Capgras syndrome presenting in an adolescent girl in the Caribbean. West Indian Medical Journal 2013;62:95-98.

63. Goldfarb AI, Weiner MB: The Capgras syndrome as an adaptational maneuver in old age. The American Journal of Psychiatry 1977;134:1434-1436.

64. Grignon S, Trottlier M: Capgras syndrome in the modern era: self-misidentification on an ID picture. Canadian Journal of Psychiatry 2005;50:74-75.

65. Hay GG: Electroconvulsive therapy as a contributor to the production of delusional misidentification. The British Journal of Psychiatry 1986;148:667-669.

66. Hayman MA, Abrams R: Capgras' syndrome and cerebral dysfunction. The British Journal of Psychiatry 1977;130:68-71.

67. Hermanowicz N: A blind man with Parkinson's disease, visual hallucinations, and Capgras syndrome. The Journal of Neuropsychiatry and Clinical Neurosciences 2002;14:462-463.

68. Hines A, Stewart JT, Catalano G: A case of Capgras syndrome related to hypothyroidism. Journal of Psychiatric Practice 2015;21:445-448.

69. Hintzen AK, Wilhelm-Gößling C, Garlipp P: Combined delusional syndromes in a patient with schizophrenia: erotomania, delusional misidentification syndrome, folie à deux and nihilistic delusion. German Journal of Psychiatry 2010;13:96-99.

70. Hirstein W, Ramachandran VS: Capgras syndrome: a novel probe for understanding the neural representation of the identity and familiarity of persons. Proceedings of the Royal Society of London B: Biological Sciences 1997;264:437-444.

71. Horikawa H, Monji A, Sasaki M, Maekawa T, Onitsuka T, Nitazaka Y, Hirano Y, Hirano S, Hashioka S, Kato T, Yoshida I: Different SPECT findings before and after Capgras' syndrome in interictal psychosis. Epilepsy \& Behavior 2006;9:189-192.

72. Hudson LA, Rollins YD, Anderson CA, Johnston-Brooks C, Tyler KL, Filley CM: Reduplicative paramnesia in Morvan's syndrome. Journal of the Neurological Sciences 2008;267:154-157.

73. Islam L, Piacentini S, Soliveri P, Scarone S, Gambini O: Capgras delusion for animals and inanimate objects in Parkinson's Disease: a case report. BMC Psychiatry 2015;15:73.

74. Jedidi H, Daury N, Capa R, Bahri MA, Collette F, Feyers D, Bastin C, Maquet P, Salmon E: Brain metabolic dysfunction in capgras delusion during Alzheimer's disease: a positron emission tomography study. American Journal of Alzheimer's Disease \& Other Dementias. 2015;30:699-706.

75. Joseph AB: Cotard's syndrome in a patient with coexistent Capgras' syndrome, syndrome of subjective doubles, and palinopsia. The Journal of Clinical Psychiatry 1986;47:605-606.

76. Joseph AB: Delusional misidentification of the Capgras and intermetamorphosis types responding to clorazepate. Acta Psychiatrica Scandinavica 1987;75:330-332.

77. Kamanitz JR, El-mallakh RS, Tasman A: Delusional misidentification involving the self. The Journal of Nervous and Mental Disease 1989;177:695-698.

78. Kaufman KR, Newman NB, Dawood A: Capgras delusion with violent behavior in Alzheimer dementia: Case analysis with literature review. Annals of Clinical Psychiatry 2014;26:e9-e13.
79. Kennedy N, Kelly B, Shanley D, Gill M: A case of co-existent Capgras and deClerambault's syndrome with a history of morbid jealousy. Irish Journal of Psychological Medicine 2000;17: 69-71.

80. Khouzam HR: Capgras syndrome responding to the antidepressant mirtazapine. Comprehensive Therapy 2002;28:238240.

81. Kimura S, Inamoto Y, Katsurada T: A Rare Case of Capgras Syndrome Observed in Wake-Amine Induced Psychosis. Psychiatry and Clinical Neurosciences 1981;35:43-54.

82. Kourany RF: Capgras syndrome variant in an $81 \frac{1}{2}$-year-old boy. Journal of the American Academy of Child Psychiatry 1983;22: 571-572.

83. Kourany RF, Williams BV: Capgras' syndrome with dysmorphic delusion in an adolescent. Psychosomatics 1984;25:715717.

84. Kumar V: Capgras syndrome in a patient with dementia. The British Journal of Psychiatry 1987;150:251.

85. Kyrtsos CR, Stahl MC, Eslinger P, Subramanian T, Lucassen EB: Capgras syndrome in a patient with Parkinson's disease after bilateral subthalamic nucleus deep brain stimulation: a case report. Case Reports in Neurology 2015;7:127-133.

86. Lebert F, Pasquier F, Steinling M, Cabaret M, Caparros-Lefebvre DC, Petit H: SPECT data in a case of secondary Capgras delusion. Psychopathology 1994;27:211-214.

87. Lewis MB, Sherwood S, Moselhy H, Ellis HD: Autonomic responses to familiar faces without autonomic responses to familiar voices: Evidence for voice-specific Capgras delusion. Cognitive Neuropsychiatry 2001;6:217-228.

88. Lewis SW: Brain imaging in a case of Capgras' syndrome. The British Journal of Psychiatry 1987;150:117-121.

89. Lipkin B: Capgras syndrome heralding the development of dementia. The British Journal of Psychiatry 1988;153:117-118.

90. Luauté JP, Bidault E: Capgras syndrome: agnosia of identification and delusion of reduplication. Psychopathology 1994;27: 186-193.

91. Luca M, Bordone A, Luca A, Patti A, Sortino G, Calandra C: Clinical features and imaging findings in a case of Capgras syndrome. Neuropsychiatric Disease and Treatment 2013;9:1095.

92. Lucchelli F, Spinnler H: A reappraisal of person recognition and identification. Cortex 2008;44:230-237.

93. Lykouras L, Typaldou M, Gournellis R, Vaslamatzis G, Christodoulou GN: Coexistence of Capgras and Frégoli syndromes in a single patient. Clinical, neuroimaging and neuropsychological findings. European Psychiatry 2002;17:234-235.

94. MacCallum WA: Capgras symptoms with an organic basis. The British Journal of Psychiatry 1973;123:639-642.

95. Malloy P, Cimino C, Westlake R: Differential diagnosis of primary and secondary Capgras delusions. Cognitive and Behavioral Neurology 1992;5:83-96.

96. Mattioli F, Miozzo A, Vignolo LA: Confabulation and delusional misidentification: a four-year follow-up study. Cortex 1999;35:413-422.

97. Matuszak J, Parra M: That's not my child: a case of Capgras syndrome. Psychiatric Times 2011;28:46.

98. Mazzone L, Armando M, De Crescenzo F, Demaria F, Valeri G, Vicari S: Clinical picture and treatment implication in a child with Capgras syndrome: a case report. Journal of Medical Case Reports 2012;6:406. 
99. McLaughlin JA, Sims A: Co-existence of the Capgras and Ekbom syndromes. The British Journal of Psychiatry 1984;145: 439-441.

100. Medic S, Obradovic DK, Zigic DM: Capgras syndrome in Parkinson's disease: A case report. Inmovement Disorders 2012; 27:S26.

101. Melca IA, Rodrigues CL, Serra-Pinheiro MA, Pantelis C, Velakoulis D, Mendlowicz MV, Fontenelle LF: Delusional Misidentification Syndromes in Obsessive-Compulsive Disorder. Psychiatric Quarterly 2013;84:175-181.

102. Mercurio EN: Capgras Syndrome associated with the use of psychoactive substances. Revista de Psiquiatría y Salud Mental (English Edition) 2011;4:96-100.

103. Merrin EL, Silberfarb PM: The Capgras phenomenon. Archives of General Psychiatry 1976;33:965-968.

104. Mishra BR, Prakash R, Mishra BN, Praharaj SK, Sinha VK: Capgras syndrome associated with Fahr's disease. The Journal of Neuropsychiatry and Clinical Neurosciences 2009;21:354355.

105. Montaldi DH, Giambrone JP, Courey NG: Capgras syndrome in a patient with myxedema. J Pediatr 1965;7:100-103.

106. Moselhy HF: Post-ictal misidentification of a city. Irish Journal of Psychological Medicine 2000;17:74-76.

107. Moreira T, Menetrey A, Carota A: Cortical oedema a link between delusional misidentification syndromes and hemiplegic migraine. Journal of Neurology, Neurosurgery \& Psychiatry 2010;81:52-53.

108. Morgado P, Freitas D, Carvalho J, Silva L, Gonçalves MM, Gonçalves J: 996 - Capgras syndrome in a three-decades nontreated schizophrenia: a case report. European Psychiatry 2013;28:1.

109. Morrison JR: Capgras delusions in a private practice. The Journal of Clinical Psychiatry 1980;41:355-356.

110. Morrison RL, Tarter RE: Neuropsychological findings relating to Capgras syndrome. Biological Psychiatry 1984;19: 1119-1128.

111. Mulholland C, O'Hara AG: An unusual case of delusional misidentification: "Delusional hermaphroditism." Psychopathology 1999;32:220-224.

112. Nabi AA: Coexisting Diogenes and Capgras syndromes. International Journal of Psychiatry in Clinical Practice 2001;5: 75-76.

113. Nagasawa H, Hayashi H, Otani K: Capgras syndrome occurring in lithium toxicity. Clinical Neuropharmacology 2012;35:204.

114. Nejad AG, Toofani K: A variant of Capgras syndrome with delusional conviction of inanimate doubles in a patient with grandmal epilepsy. Acta Neuropsychiatrica. 2006;18:52-54.

115. Nilsson R, Perris C: The Capgras syndrome: a case report. Acta Psychiatrica Scandinavica 1971;47:53-58.

116. Nishihara K, Kinoshita H, Kurotaki N, Ozawa H, Imamura A: Could subclinical hypothyroidism cause periodic catatonia with delusional misidentification syndrome? Psychiatry and Clinical Neurosciences 2010;64:338.

117. O'connor M, Walbridge M, Sandson T, Alexander M: A Neuropsychological Analysis of Capgras Syndrome. Cognitive and Behavioural Neurology 1996;9:265-271.

118. O'Dwyer JM: Coexistence of the Capgras and de Clérambault's syndromes. The British Journal of Psychiatry 1990;156: 575-577.

Capgras' Delusion: A Meta-Analysis of Case Reports
119. O’Reilly R, Malhotra LA: Capgras syndrome - an unusual case and discussion of psychodynamic factors. The British Journal of Psychiatry 1987;151:263-265.

120. Pachana NA, Drake E, van Gorp WG, Sorensen D: Similarities of neuropsychological presentation in two cases of Capgras syndrome with comorbid depression. New Zealand Journal of Psychology 1999;28:55.

121. Paillère-Martinot ML, Dao-Castellana MH, Masure MC, Pillon B, Martinot JL: Delusional misidentification: a clinical, neuropsychological and brain imaging case study. Psychopathology 1994;27:200-210.

122. Papageorgiou C, Lykouras L, Ventouras E, Uzunoglu N, Christodoulou GN: Abnormal P300 in a case of delusional misidentification with coinciding Capgras and Fregoli symptoms. Progress in Neuro-Psychopharmacology and Biological Psychiatry 2002;26:805-810.

123. Polonowita A, de Silva FP, Baillie R: Capgras syndrome: two case reports. The New Zealand Medical Journal 1978;88:445446.

124. Preskown SH, Reveley A: Pseudohypoparathyroidism and Capgras Syndrome. The British Journal of Psychiatry 1978; 133:34-37.

125. Raese J, Ibrahim F: Psychosis and Capgras delusions in a patient diagnosed with Cogan's syndrome. Clinical Case Reports and Reviews 2015;1:6-9.

126. Ranjan S, Chandra PS, Gupta AK, Prabhu S: Clonal pluralization of self, relatives and others. Psychopathology 2007;40: 465-467.

127. Rapinesi C, Kotzalidis GD, Casale AD, Ferri VR, Di Pietro S, Scatena P, Serata D, Danese E, Sani G, Koukopoulos AE, Angeletti G: Treatment-resistant, five-year long, postpartum-onset Capgras episode resolving after electroconvulsive therapy. The International Journal of Psychiatry in Medicine 2015;49: 227-234.

128. Reimers K, Emmert N, Shah H, Benedict RH, Szigeti K: Capgras-like visual decomposition in Lewy body dementia with therapeutic response to donepezil. Neurology: Clinical Practice 2014;4:467-469.

129. Roane DM, Rogers JD, Robinson JH, Feinberg TE: Delusional misidentification in association with parkinsonism. The Journal of Neuropsychiatry and Clinical Neurosciences 1998; 10:194-198.

130. Romanik RL, Snow SU: Two cases of Capgras' syndrome. The American Journal of Psychiatry 1984;141:720.

131. Salvatore P, Bhuvaneswar C, Ebert D, Maggini C, Baldessarini RJ: Cycloid psychoses revisited: case reports, literature review, and commentary. Harvard Review of Psychiatry 2008;16:167180.

132. Salviati M, Bersani FS, Macrì F, Fojanesi M, Minichino A, Gallo M, De Michele F, Chiaie RD, Biondi M: Capgras-like syndrome in a patient with an acute urinary tract infection. Neuropsychiatr Dis Treat 2013;9:139-142.

133. Sathe H, Karia S, Desousa A, Shah N: Capgras Syndrome: A Case Report. Paripex-Indian Journal of Research 2014;3:134.

134. Sautter SW, Briscoe L, Farkas K: A neuropsychological profile of Capgras syndrome. Neuropsychology 1991;5:139.

135. Shah PJ, Dewar IG: An unusual variant of a delusional misidentification syndrome. The Canadian Journal of Psychiatry/ La Revue Canadienne de Psychiatrie 1995;40:158-159. 
136. Sharma A, Garuba M, Egbert M: Capgras syndrome in a patient with multiple sclerosis: a case report. Primary Care Companion to the Journal of Clinical Psychiatry 2009;11:274.

137. Shiotuki H, Motoi Y, Hattori N, Mizuno Y: Effect of donepizil on Capgras syndrome in Parkinson's disease with dementia: A single case report: P1151. Movement Disorders 2006;21:S647.

138. Silva JA, Ferrari MM, Leong GB, Weinstock R: The role of mania in the genesis of dangerous delusional misidentification. Journal of Forensic Science 1997;42:670-674.

139. Silva JA, Leong GB: Capgras syndrome during the wake and dream state. Canadian Journal of Psychiatry. Revue Canadienne de Psychiatrie 2000;45:299-300.

140. Silva JA, Leong GB, Garza-Treviño ES, Le Grand J, Oliva D, Weinstock R, Bowden CL: A cognitive model of dangerous delusional misidentification syndromes. Journal of Forensic Science 1994;39:1455-1467.

141. Silva JA, Leong GB, Longhitano M, Botello TE: Delusion of fetal duplication in a Capgras patient. The Canadian Journal of Psychiatry 1991;36:46-47.

142. Silva JA, Leong GB, Rhodes LJ, Weinstock R: A new variant of "subjective" delusional misidentification associated with aggression. Journal of Forensic Science 1997;42:406-610.

143. Silva JA, Leong GB, Weinstock R, Boyer CL: Capgras syndrome and dangerousness. Journal of the American Academy of Psychiatry and the Law Online 1989;17:5-14.

144. Silva JA, Leong GB, Weinstock R, Ruiz-Sweeney M: Delusional misidentification and aggression in Alzheimer's disease. Journal of Forensic Science 2001;46:581-585.

145. Silva JA, Sharma KK, Leong GB, Weinstock R: Dangerousness of the delusional misidentification of children. Journal of Forensic Science 1992;37:830-838.

146. Signer SF, Benson DF: Two cases of Capgras symptom with dysmorphic (somatic) delusions. Psychosomatics 1987;28: 327-328.

147. Signer SF, Isbister SR: Capgras syndrome, de Clerambault's syndrome, and folie deux. The British Journal of Psychiatry 1987;151:402-404.

148. Sinkman A: The syndrome of Capgras. Psychiatry: Interpersonal and Biological Processes 2008;71:371-378.

149. Spiegel DR, Laroia R, Samuels D: A possible case of Capgras syndrome after a right anterior cerebral artery cerebrovascular accident treated successfully with mirtazapine. The Journal of Neuropsychiatry and Clinical Neurosciences 2008;20:494.

150. Stewart JT: Capgras syndrome related to diazepam treatment. Southern Medical Journal 2004;97:65-67.

151. Stein RM, Lipper S: An obsessional variant of Capgras symptom: a case report. Bulletin of the Menninger Clinic 1988;52:52.

152. Su KP, Hsu CY, Hsieh SC, Shen WW: Magnetic resonance imaging findings in patients with delusional disorder due to diffuse cerebrovascular disease: a report of seven cases. Psychiatry and Clinical Neurosciences 2001;55:121-126.

153. Sullivan JL, Cavenar JO, Maltbie AA, Silverstein E: Capgras syndrome- a biochemical marker? The Journal of Nervous and Mental disease 1978;166:275-279.

154. Sumners D. Believing your husband has been replaced by an impostor because you have a pituitary tumour. British Medical Journal (Clinical research ed.) 1984;289:699.

155. Takaoka, Norikatsu Ikawa, Nobuya Niwa K: $\oslash$ Alice in Wonderland 'syndrome as a precursor of delusional misidentifica- tion syndromes. International Journal of Psychiatry in Clinical Practice 2001;5:149-151.

156. Thiel CM, Studte S, Hildebrandt H, Huster R, Weerda R: When a loved one feels unfamiliar: a case study on the neural basis of Capgras delusion. Cortex 2014;52:75-85.

157. Thode KI, Faber RA, Chaudhuri TK: Delusional misidentification syndrome: right-hemisphere findings on SPECT. The Journal of Neuropsychiatry and Clinical Neurosciences 2012; 24:E22-E23.

158. Thompson AE, Swan M: Capgras' syndrome presenting with violence following heavy drinking. The British Journal of Psychiatry 1993;162:692-694.

159. Thompson MI, Silk KR, Hover GL: Misidentification of a city: delimiting criteria for Capgras syndrome. The American Journal of Psychiatry 1980;137:1270-1272.

160. Tin TC: The Syndrome of Capgras: A Case Report. Singapore Medical Journal 1979;20:409-411.

161. Sidoti V, Lorusso L: Multiple sclerosis and Capgras' syndrome. Clinical Neurology and Neurosurgery 2007;109:786787.

162. Todd J, Dewhurst K, Wallis G: The syndrome of Capgras. The British Journal of Psychiatry 1981;139:319-327.

163. Torales J, Rodríguez H, Arce A, Moreno M, Riego V, Chávez E, Capurro M: Olanzapine in the treatment of Capgras Syndrome: a case report. International Journal of Culture and Mental Health 2014;7:224-228.

164. Tueth MJ, Cheong JA: Successful treatment with pimozide of Capgras syndrome in an elderly male. Topics in Geriatrics 1992;5:217-219.

165. Turkiewicz G, Zanetti MV, Zung S, Cordeiro Q: Coexistence of Capgras and Frégoli syndromes associated to frontotemporal volume reduction and cerebral white matter hyperintensities. Archives of Clinical Psychiatry (São Paulo) 2009;36:240-243.

166. Turtzo LC, Kleinman JT, Llinas RH: Capgras syndrome and unilateral spatial neglect in nonconvulsive status epilepticus. Behavioural Neurology 2008;20:61-64.

167. Vartzopoulos D, Vartzopoulos I: A variant of the syndrome of subjective doubles. American Journal of Psychiatry 1991;148: 394-395.

168. Waldeck T, Wyszynski B, Medalia A: The relationship between Usher's syndrome and psychosis with Capgras syndrome. Psychiatry 2001;64:248-255.

169. Waziri R: The Capgras phenomenon: cerebral dysfunction with psychosis. Neuropsychobiology 1978;4:353-359.

170. Weinstein EA: The classification of delusional misidentification syndromes. Psychopathology 1994;27:130-135.

171. Wenzel T, Sibitz I, Kieffer W, Strobl R: Capgras syndrome and functional psychosis in 2 survivors of torture. Psychopathology 1999;32:203-206.

172. Weston MJ, Whitlock FA: The Capgras syndrome following head injury. The British Journal of Psychiatry 1971;119:25-31.

173. Wilcox J, Waziri R: The Capgras symptom and nondominant cerebral dysfunction. The Journal of Clinical Psychiatry 1983; 44:70-72.

174. Wilcox JA: A case of Capgras' phenomenon. Australian and New Zealand Journal of Psychiatry 1984;18:391-392.

175. Wright S, Young AW, Hellawell DJ: Sequential Cotard and Capgras delusions. British Journal of Clinical Psychology 1993;32:345-349. 


\section{References}

1 Halligan PW, David AS. Cognitive neuropsychiatry: towards a scientific psychopathology. Nat Rev Neurosci. 2001 Mar;2(3):209-15.

2 Langdon R, Coltheart M. The cognitive neuropsychology of delusions. In: Coltheart M, Davies M, editors. Pathologies of Belief. London: Blackwell Publishers; 2000. p. 183-216.

3 Capgras J. Reboul-Lachaux. L'illusion des 'sosies' dans un délire systématisé chronique. Hist Psychiatry. 1994;5:119-33.

4 Ellis HD, Young AW. Accounting for delusional misidentifications. Br J Psychiatry. 1990 Aug;157(2):239-48.

5 Coltheart M, Menzies P, Sutton J. Abductive inference and delusional belief. Cogn Neuropsychiatry. 2010 Jan;15(1):261-87.

6 Capgras J, Reboul-Lachaux. L'illusion des 'sosies' dans un délire systématisé chronique. Hist Psychiatry. 1994;5:119-33.

7 Capgras J, Carette J. Illusion des sosies et complexe d'Oedipe. Ann Med Psychol (Paris). 1924;82:48.

8 Gluckman LK. A case of Capgras syndrome. Austral NZ J Psychiatry. 1968;2(1):39-43.

9 Dennett D. Kinds of Minds: Towards an Understanding of Consciousness. New York: Basic Books; 1996. p. 111.

10 Enoch D, Ball H. Capgras' syndrome. In Uncommon Psychiatric Syndromes. 4th ed. London: Arnold; 2001. p. 1-19.

11 Salvatore P, Bhuvaneswar C, Tohen M, Khalsa HM, Maggini C, Baldessarini RJ. Capgras' syndrome in first-episode psychotic disorders. Psychopathology. 2014;47(4):261-9.

12 Fishbain DA. The frequency of Capgras delusions in a psychiatric emergency service. Psychopathology. 1987;20(1):42-7.

13 Fleminger S, Burns A. The delusional misidentification syndromes in patients with and without evidence of organic cerebral disorder: a structured review of case reports. Biol Psychiatry. 1993 Jan;33(1):22-32.

14 Edelstyn NM, Oyebode F. A review of the phenomenology and cognitive neuropsychological origins of the Capgras syndrome. Int J Geriatr Psychiatry. 1999 Jan;14(1):48-59.

15 Vandenbroucke JP. In defense of case reports and case series. Ann Intern Med. 2001 Feb; 134(4):330-4.
16 Trabert W. 100 years of delusional parasitosis Meta-analysis of 1,223 case reports. Psychopathology. 1995;28(5):238-46.

17 Poole NA, Wuerz A, Agrawal N. Abreaction for conversion disorder: systematic review with meta-analysis. Br J Psychiatry. 2010 Aug; 197(2):91-5.

18 Enoch MD. The Capgras syndrome. Acta Psychiatr Scand. 1963;39(3):437-62.

19 Förstl H, Almeida OP, Owen AM, Burns A, Howard R. Psychiatric, neurological and medical aspects of misidentification syndromes: a review of 260 cases. Psychol Med. 1991 Nov;21(4):905-10.

20 Merrin EL, Silberfarb PM. The Capgras phenomenon. Arch Gen Psychiatry. 1976 Aug; 33(8):965-8.

21 Christodoulou GN. The syndrome of Capgras. Br J Psychiatry. 1977 Jun;130(6):556-64.

22 De Pauw KW, Szulecka TK. Dangerous delusions. Violence and the misidentification syndromes. Br J Psychiatry. 1988 Jan;152(1):916.

23 Campbell J. Rationality, Meaning, and the Analysis of Delusion. Philos Psychiatry Psychol. 2001;8(2):89-100.

24 Berrios G. Delusions. In The History of Mental Symptoms: Descriptive Psychopathology Since the Nineteenth Century. Cambridge: Cambridge University Press; 1996. p. 114.

25 Maher BA. Delusion: contemporary etiological hypotheses. Psychiatr Ann. 1992;22(5): 260-8.

26 Lishman A. Organic Psychiatry: The Psychological Consequences of Cerebral Disorder. London: Blackwell Scientific Publications; 1978.

27 Staton RD, Brumback RA, Wilson H. Reduplicative paramnesia: a disconnection syndrome of memory. Cortex. 1982 Apr;18(1): 23-35.

28 Young AW. Wondrous strange: the neuropsychology of abnormal beliefs. In: Coltheart M, Davies M, editors. Pathologies of Belief. Oxford: Blackwell; 2000. p. 47-73.
29 Davies M, Egan A. Delusion: cognitive approaches - Bayesian inference and compartmentalization. In Fulford KWM, Davies M, Gipps RGT, Graham JZ, Sadler G, Stanghellini G, et al, editors. The Oxford Handbook of Philosophy and Psychiatry. Oxford: Oxford University Press; 2013, p. 689-727.

30 Cutting J. The Right Cerebral Hemisphere and Psychiatric Disorders. Oxford: Oxford University Press; 1990

31 Bell V, Marshall C, Kanji Z, Wilkinson S, Halligan P, Deeley Q. Uncovering Capgras delusion using a large-scale medical records database. BJPsych Open. 2017 Aug;3(4):179-85.

32 Currell EA, Werbeloff N, Hayes JF, Bell V. Cognitive neuropsychiatric analysis of an additional large Capgras delusion case series. Cogn Neuropsychiatry. 2019 Mar;24(2):12334.

33 Bobes MA, Góngora D, Valdes A, Santos Y, Acosta Y, Fernandez Garcia Y, et al. Testing the connections within face processing circuitry in Capgras delusion with diffusion imaging tractography. Neuroimage Clin. 2016 Jan; 11:30-40.

34 White PD, Rickards H, Zeman AZ. Time to end the distinction between mental and neurological illnesses. BMJ. 2012 May;344(may24 1):e3454.

35 Martin JB. The integration of neurology, psychiatry, and neuroscience in the 21st century. Am J Psychiatry. 2002 May;159(5):695-704.

36 Bailey S, Burn W, Craddock N, Mynors-Wallis L, Tyrer P. Suggested merger of mental and neurological illnesses is premature. BMJ. 2012 Jul;345 jul09 2:e4577.

37 Crossley NA, Scott J, Ellison-Wright I, Mechelli A. Neuroimaging distinction between neurological and psychiatric disorders. $\mathrm{Br} \mathrm{J}$ Psychiatry. 2015 Nov;207(5):429-34.

38 Horikawa H, Monji A, Sasaki M, Maekawa T, Onitsuka T, Nitazaka Y, et al. Different SPECT findings before and after Capgras' syndrome in interictal psychosis. Epilepsy Behav. 2006 Aug;9(1):189-92.

39 Malloy P, Cimino C, Westlake R. Differential diagnosis of primary and secondary Capgras delusions. Neuropsychiatry Neuropsychol Behav Neurol. 1992;5(2):83-96. 